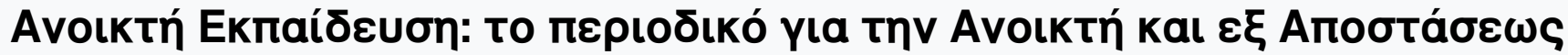

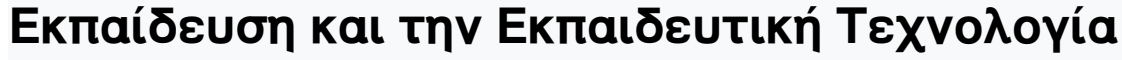

Tóp. 12, Ap. 2 (2016)

Volume 12

Number 2

2016

\section{Open}

\section{Education}

The Journal for Open and Distance Education and Educational Technology

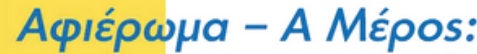

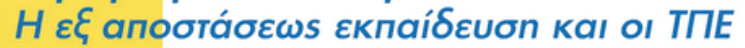

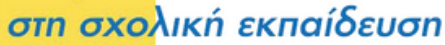

\section{(a)}

A periodical electronic publication of the Scientific Association: Hellenic Network of Open and Distance Education
Digital Student Conference Platform Implementation: The case study of the "Research Project" course

Vasileios Orfanakis, Stamatios Papadakis, Michail Kalogiannakis, Maria Ampartzaki, Kostas Vassilakis doi: $10.12681 /$ jode. 10871

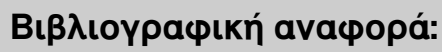




\title{
Digital Student Conference Platform Implementation: The case study of the "Research Project" course
}

\author{
Vasileios Orfanakis \\ Secondary Education Teacher, Postgraduate Student \\ Technological Educational Institute of Crete \\ Department of Applied Informatics \& Multimedia \\ vorfan@gmail.com \\ Stamatios Papadakis \\ $\mathrm{PhD}$, University of Crete \\ Department of Preschool Education \\ Secondary Education Teacher \\ stpapadakis@gmail.com \\ Michail Kalogiannakis \\ Assistant Professor \\ Department of Preschool Education \\ Faculty of Education \\ University of Crete, Crete, Greece \\ mkalogian@edc.uoc.gr \\ Maria Ampartzaki \\ Assistant Professor \\ Department of Preschool Education \\ Faculty of Education \\ University of Crete, Crete, Greece \\ mabarjaki@edc.uoc.gr \\ Kostas Vassilakis \\ Professor of Informatics \\ Science Department \\ Technological Education Institute of Crete, Greece \\ kostas@cs.teicrete.gr
}

\begin{abstract}
Today, during the 'fourth industrial revolution' which is led by the Internet and the digital ecosystem it creates, schools are expected to achieve the development of not only the functional skills of literacy and numeracy but also of general knowledge. The apparent inadequacy of the standardized education system to respond to the needs and interests of $21^{\text {st }}$-century students urges researchers to adopt new forms of teaching as meaningful and high-quality teaching requires a more active use of innovative educational methods and tools. With the rapid development of IT globally, there is a tendency to utilize the capabilities of e-learning as a mode of distance learning since it can function both independently of and in conjunction with conventional teaching. The varied applications of Web 2.0 tools create new possibilities in the educational sector. It provides the ability to develop innovative educational methods that transform students from passive recipients of information to knowledge creators through an active involvement in the learning process often within a modern interactive environment. This study presents the results of the implementation of a teaching intervention, with the use of a flexible and student-centered web system
\end{abstract}


developed and used as complementary to the 'Research Project' course during the first term of the 2015-2016 school year. The ultimate goal of this effort was to highlight and consequently incorporate the use of a digital platform for student conferences which we implemented in schools as a means to research, learning, and skill development. The students had the opportunity to participate in a digital community which employed distance learning tools for communication, cooperation, and learning during a digital conference in which they had leading roles as writers and reviewers. The initial results of the pilot study indicated that the use of the digital platform increased the interest of students, supported the development of various skills and contributed to the overall improvement of the teaching and learning process.

\section{Keywords}

Educational Technology; Web2.0; Digital Student Conference; Innovation; Research Project

\section{Introduction}

Societies are becoming increasingly digital, a fact which raises the demands for digital knowledge. Education and training must respond to this need, which requires investments in infrastructure, organisational changes, digital devices and knowledge in the wider educational community as well as the creation of digital (and open) educational resources and high-quality educational software (Official Journal of the European Union, 2015). Education and training must utilise the new developments in ICT and adopt innovative and dynamic pedagogical processes by adapting and updating content according to the dynamics of time, and up to date with the transformation of society (Anastasiades, 2005; Kalogiannakis, 2010; Papadakis, Kalogiannakis, Orfanakis \& Zaranis, 2014; Papadakis, Kalogiannakis, Orfanakis \& Zaranis, 2016). The majority of the educational community is aware of the contribution of ICT as a cognitive tool within a constructive and socio-cognitive approach to teaching and learning (Jimoyiannis, 2012; Spanos \& Sofos, 2014). The development of technology has sparked the debate over the educational uses of the Internet, and the support of conventional teaching by modern Web 2.0 applications (Jimoyiannis, Tsiotakis, Roussinos \& Siorenta, 2013; Panagiotakopoulos, Tsiatsos, Lionarakis \& Tzanakos, 2015). The rapid online technological development of recent years, especially in the form of Web 2.0 applications, has created a new reality in both the conventional and digital educational sector (McBrien, Cheng \& Jones, 2009), significantly transforming the environment of communication and interaction by the use of modern and conventional learning environments (Panagiotakopoulos, Lionarakis \& Xenos, 2003; Stasinakis \& Kalogiannakis, 2015). The interest of research in finding complementary forms of education with the use of ICT is based on the finding that conventional primary and secondary educational systems are becoming unable to meet all the needs and interests of students globally (Anastasiades, 2005; Chatziplis, Vassala \& Lionarakis, 2007; Psycharis, Chalatzoglidis \& Kalogiannakis, 2013).

The problem with effectively integrating the Internet into education is not just focused on the improvement of traditional teaching practices but also on the reform of the wider pedagogical framework and the effective reinforcement of the learning process (Jimoyiannis \& Angelaina, 2012). Most international research validates the 
contribution of these new media in creating innovative electronic learning environments, allowing the adoption of pedagogical processes rooted in participatory methods by the educational community (Kalogiannakis, 2008), thereby facilitating cooperation and communication among students of different schools (Anastasiades et al., 2010; Panagiotakopoulos et al., 2015). The research community is constantly seeking new and effective ways to incorporate those forms of ICT in conjunction with, and complementary to, conventional education for the provision and support of alternative educational programs, and lessons which are, for various reasons not delivered in the classroom, as well as topics which are not included in the curriculum but nonetheless gain the interest of students (Chatziplis et al., 2006; Stasinakis \& Kalogiannakis, 2015). Various targeted Web 2.0 services can offer valuable service to all levels of secondary education via distance learning. The term eLearning as a method is defined as education provided from a distance, aiming at both young students and adults (Bradley, 2003; Roblyer, 2003). A major advantage of distance learning is that it can function independently as well as complementary to conventional education (UNESCO, 2002). These innovative environments not only aid students in developing a more positive stance towards ICT, improving their ICT skills but also in actively acquiring new knowledge and collaborating with other students to exchange knowledge and experiences (Anastasiades \& Kotsidis, 2013). Realising that a complementary distance learning system can offer solutions to the teaching process and taking into account the various issues of conventional secondary education we managed to develop a student-centred distance learning system whose goal is to improve skills, instead of formaly testing the existence of knowledge.

The present study introduces this system and the initial results of its assessment, discussing the effectiveness of the virtual conference as a complementary distance learning tool and its reception by the student community.

\section{The need to adopt innovation in education}

In today's rapidly changing socioeconomic environment one of the main goals of educational policy is the improvement of teaching methods so that learning becomes more and more attractive and efficient for learners (Jimoyiannis et al., 2013). In the age of information society, schools are obliged to be creative, experiential and studentcentred and treat students as multifaceted entities (Kalogiannakis, 2010). The entire educational community recognises that education should not primarily aim for the accumulation of knowledge and information, but for making students capable of seeking and developing solutions to problems, exploring, judging results, discerning connections - and generally nurturing not only convergent intellect, but also divergent (creative) thinking (Maureen, 2000).

In this context, the systematic assessment of learning techniques, particularly those that enhance team building such as role-playing, resolution in the context of debate, brainstorming, utilization of simulations, work, plans (projects), etc., which can be used with proper adjustment and careful application by the teacher both in conventional and distance learning is particularly important (Palloff \& Pratt, 1999). In the case of distance learning the teacher uses ICT to support the educational process, increase participation and motivate learners (Xie, Debacker \& Ferguson, 2006).

Thus, the selection of teaching and learning resources is considered to be a very important process (Panagiotakopoulos et al., 2015), as with appropriate use, it effectively promotes learning and transforms students from passive recipients to creators of knowledge (Kalogiannakis, 2010). Additionally, when the learning process 
takes place in a modern interactive environment students are placed at the center of the educational process exercising independent thinking in order to to 'learn, act and coexist', in short, to develop the so-called 21st century skills (Panagiotakopoulos et al., 2003; Papastergiou, Antoniou \& Apostolou, 2011; Apostolou, Antoniou \& Papastergiou, 2014).

\section{The 'Research Project' course as innovation in secondary education}

Educational innovation is every widespread intervention, which is based on pioneering and innovative teaching principles and ideas that bring forth significant changes in attitudes, practices, roles and the whole school culture (Matsagouras, 2011). In the field of secondary education, an innovation that was introduced rather late in comparison with educational systems of other developed countries is the "Research Project course" which was only established in September 2011 as a separate section of the mandatory curriculum of the "New Highschool" (Stasinakis \& Kalogiannakis, 2015). Establishing educational research and cooperation practices between teachers and students and creating a learning culture that encourages initiative, choice, investigation, experimentation and both individual and group responsibility in general (that is the $21^{\text {st }}$ century skills), the introduction of projectbased learning during the 2011-12 academic year in the Greek educational system aspired changes in the roles of teachers and students. The term 'project-based learning' is defined as a learning method in which students acquire knowledge and skills by carrying out investigation and trying to answer complex questions, solve problems or meet challenges (Bell, 2010).

The 'educational philosophy' of 'research projects', are addressed by four basic pedagogic principles as shown in Figure 1 (Matsagouras, 2011).

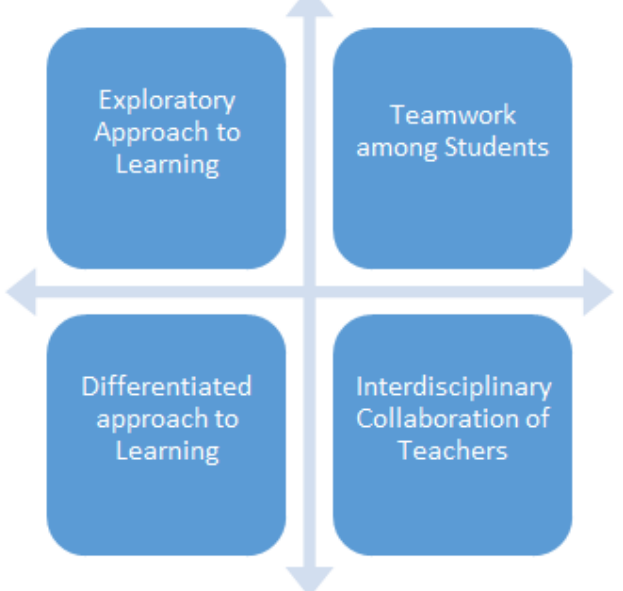

Figure 1. The 'educational philosophy' of 'research projects' (Matsagouras, 2011)

The main characteristics of the research project are the active role of students and the acquisition of meaningful knowledge for multiple benefits in the learning process (Figure 2). 


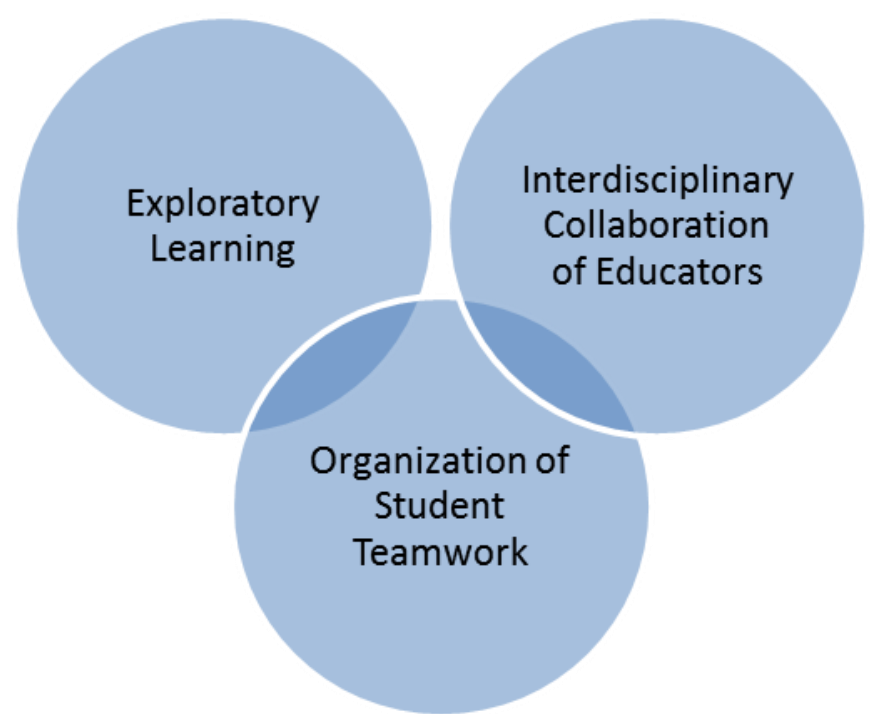

Figure 2. Benefits of the 'Research Project' course (Matsagouras, 2011)

The teaching of the course was supported by short training seminars and a course guide that described the principles, procedures, topics and assessment of the "Research Project" (Matsagouras, 2011). Similar courses were introduced a few years ago in other European counties, as, for example, the Supervised Personal Work course in France (Stasinakis \& Kalogiannakis, 2015). However, despite the benefits in functional understanding, attitude development, investigative skills and management of unstable situations and conflict (Psycharis et al., 2013), the introduction of research projects in practice has not shown the expected results. In addition to the institutional problems which arose immediately, (such as the downgrading of the course through the reduction of teaching hours or the number of teachers and administrative decisions which inhibited the development of interdisciplinarity), there were problems associated with the implementation of research projects at a class level. The problems according to Theofanellis (2014) were the following:

- There was often a lack of interest in some students that lead to problematic involvement. They did not share the same level of involvement or were completely uninvolved leaving the weight of the work to fall onto the rest of the group.

- Often students did not want to present their work to the rest of the educational community; it was quite common for timider students to be reluctant to be exposed to the rest of the educational community. Thus, on one hand, they were not motivated and on the other, without comments from teachers and classmates, students had no way to gauge the value of their work. This was a particularly important feature as students who know that their work will be seen by others are motivated to make more effort. As students and teachers were using a completely different form of assessment in standard courses, assessment in the context of research project was another issue that had to be clarified and resolved.

\section{The necessity of creation of a digital student conference platform}

As it is evident, the implementation of a project aims more at students experiencing the process and 'learning how to learn' than acclaiming knowledge in the traditional context of a subject matter (Stasinakis \& Kalogiannakis, 2015). The ultimate goal of such a activity course is that students develop nodal skills such as communication and teamwork skills, the pursuit, collection and use of information, and the ability to use 
ICT tools for problem-solving with an emphasis on the exploitation of Internet services (Jimoyiannis et al., 2013). Web 2.0 tools provide convenience, ease of access and multifaceted possibilities to students and teachers which can contribute to the implementation of quality complementary distance learning (Anastasiades, 2005; Jimoyiannis, 2012; Panagiotakopoulos et al., 2015).

As a subject of the formal curriculum, the research project should be assessed and evaluated. However, the concept of performance in research is much broader and should not be measured solely by the final product because the assessment of students should meet the multifaceted objectives of the course and motivate them towards participation, teamwork and research (Stasinakis \& Kalogiannakis, 2015). The criteria which are used or should be used for assessment in the context of the research project is originality and application of the scientific method, setting and keeping a schedule, the use of ICT, the ability to interpret, correlate and exploit data, the ability to evaluate and review options, processes and roles if and when this is deemed necessary (Matsagouras, 2011). Also, the quality of the presentation is based on criteria such as attracting the audience's interest, and inventiveness in the combined use of speech, images, sound, etc., is considered important (Psycharis et al., 2013). Undoubtedly, a prerequisite for the implementation of the research projects is the existence of necessary regulatory instruments which are not provided in Greek schools. More often than not, the classrooms are not conducive to creating a climate of cooperation and 'relaxed' work. Often students are forced to work in school facilities which are unsuitable most frequently because of the inadequate infrastructure.

Taking into consideration the various aforementioned deterrents we were led to the creation of a modern interactive digital environment to support the implementation of the research projects with an emphasis on the use of Internet services and Web 2.0 in particular. The general philosophy that permeated the use of this digital environment was to put the students at the center of the educational effort, making them responsible for their own progress and development (Anastasiou, Androutsou \& Georgalas 2014). Through the use of web applications both intraschool and at the interschool level, students learnt to share information and ideas, argue, debate and, ultimately, transform the creation of a research paper into a highly value-added educational process (Psycharis et al., 2013).

Specifically, the platform supports digital student conferences which can be held both at school (intraschool) and between an unlimited number of schools (interschool). Once registered in the platform, students and teachers can fully simulate the stages of a physical scientific conference under the conditions of project-based learning. More specifically, the students-authors can upload their work, have it assessed, receive criticism, send their revised drafts and finally present their work in the plenary session. The teacher may have a dual role in this context, fulfilling both the role of coordinator (organizing committee) and evaluator of the project or that of the organizer and share a review with the students (review panel). Essentially, the role of the teacher shifts to that of mentor and 'travel companion' in the conquest of knowledge with his/her students. Similarly, the implementation of student conferences on a multi-school level, without geographic limitations, can be organised. Such student-oriented activities consisting of group or individual and intra-school or interschool activities are considered to provide various benefits to the educational process. Students that upload their work for assessment in the context of a conference, take on the responsibility for the completion of the activities they are engaged with. At this point it should be noted that this focus on students, both in terms of teaching 
and assessment, does not diminish the importance of the teacher's role, who sets the goals of particular activities and seeks to expand students' interests and academic skills.

Additionally, it is thought that it enables introverted students to engage more actively hence transforming the learning process to a much more pleasant occurrence. It gives such students the opportunity to perform without the stress and pressure of competition by tansforming research to a school project that promotes mutual support, aid, and control, without affecting the self-image and self-esteem of students (Stasinakis \& Kalogiannakis, 2015). Ultimately, we believe such a student-centered activity will result in the wider involvement of students and help them realize their responsibilities, both towards the group and the final, delivered product, increasing their self-esteem at the same time.

In an era of rapid development and application of IT in all areas of human activity, it is imperative for students to develop creative practices through the use of ICT (Kalogiannakis, 2010; Papadakis et al., 2014, Papadakis et al., 2016), and in this respect the use of a digital platform developed for the occurrence of student conferences can provide significant assistance. Regarding ICT, the use of the Internet is undoubtedly considered to be particularly pleasant for students, as it offers rich audiovisual material while simultaneously creating incentives for learning, and making coursework accessible and understandable (Anastasiou et al., 2014). Also, students using new IT tools (Papadakis et al., 2014) and knowledge of new media and the possibilities of Web 2.0 are given the opportunity to develop higher-order skills, and a new culture of learning whilst they build a meaningful relationship with knowledge (Jimoyiannis, 2012).

\section{Technological Infrastructure}

As we have already mentioned, to make the 'Research Project' course more attractive, we created a platform which integrates social networking and conference services. Technologically, it is based on free and open source software (WordPress, BuddyPress and BigBlueButton) and it is available on-line at http://schedu.teicrete.gr/conf/.

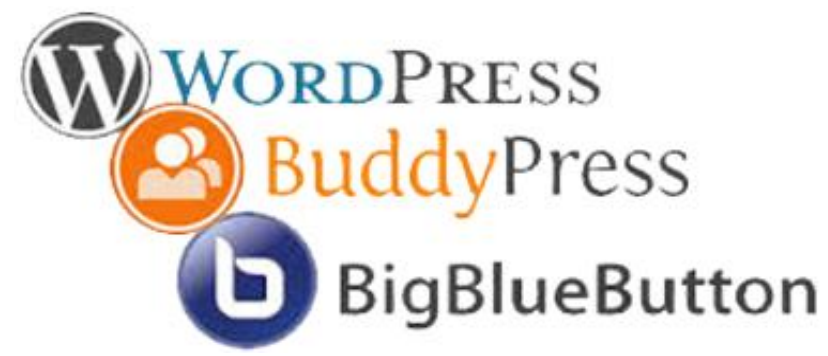

Figure 3: Main platform components

Hosting is offered by a Virtual Machine provided by the Virtualization infrastructure at the Control Center and Network Management Center (NMC) of TEI, Crete (https://www.nmc.teicrete.gr/). The characteristics and minimum requirements of software and hardware are presented in Table1. 
Table 1. The server's software and hardware features - requirements

\begin{tabular}{|l|l|l|l|}
\hline \multicolumn{2}{|c|}{ Server requirements } & \multicolumn{2}{c|}{ Server software characteristics } \\
\hline Description & Size & Description & Version \\
\hline CPU & 1 & Ubuntu OS & 14.04 .2 LTS x64 \\
\hline RAM & $2 \mathrm{~GB}$ & Apache & 2.4 .7 \\
\hline HDD & $50 \mathrm{~GB}$ & PHP & 5.5 .9 \\
\hline \multirow{4}{*}{} & MySQL & 5.5 .44 \\
\cline { 2 - 4 } & Tomcat & 7.0 .52 \\
\cline { 2 - 4 } & Java OpenJDK & $1.7 .0 \_79$ \\
\cline { 2 - 4 } & Nginx & 1.4 .6$. \\
\cline { 2 - 3 } & &
\end{tabular}

The Nginx Web Server (http://nginx.org/) is being used to support the videoconferencing system BigBlueButton while an Apache Web Server (http://www.apache.org/) runs as a secondary server for the WordPress platform. The architecture of the platform is shown in Figure 4.

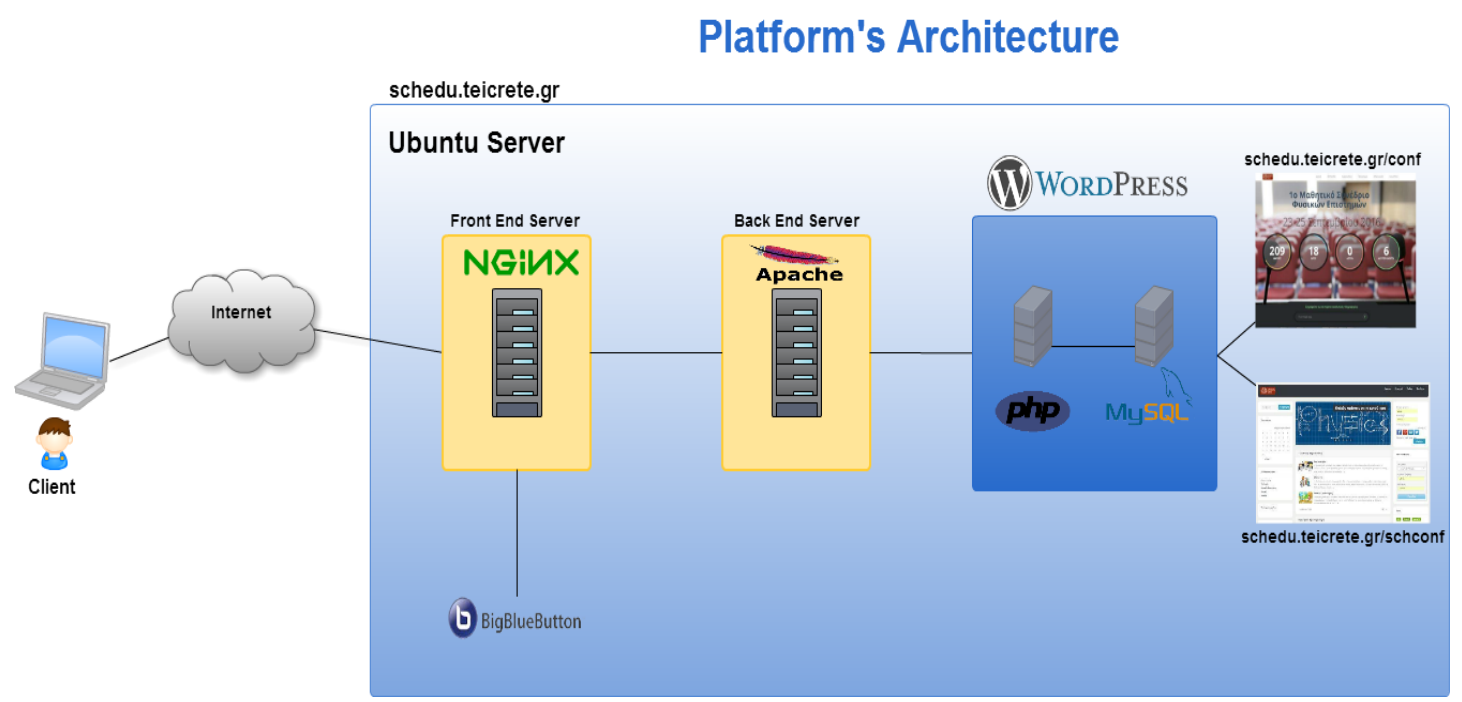

Figure 4: The Platform's architecture

\section{WordPress}

The choice of the Content Management System (CMS) WordPress (https://el.wordpress.org/) was made because we believe that it gathers all the features and capabilities that should be included in a web content management environment, which is basically geared to non-professionals. In summary, it is relatively easy to use, scalable, affordable (no cost) and has a great support community. The requirements for the installation of WordPress are minimal, enabling it to run seamlessly in any storage service web that supports the PHP programming language and MySQL database. It can run on either Apache or IIS servers (web servers). Regarding management and content visibility, WordPress features all the necessary tools for use by a teacher or school unit (Papadakis \& Orfanakis, 2014a; 2014b).

Although WordPress is a newer CMS compared with Joomla and Drupal and while initially started as a blog builder, it has been rising and spreading rapidly in recent years. It was awarded the distinction of Overall Best Open Source CMS Award in the '2009 Open Source CMS Awards' (Leary, 2010). The popularity of WordPress among Internet users is shown by the charts in Figure 5. According to data from the 
Google Trends website (http://goo.gl/Mm8UyH) (Google Trends, 2016), not only is WordPress the most popular CMS, but also the forecast shows that this trend will become even more popular worldwide in the near future.

Compare search terms -

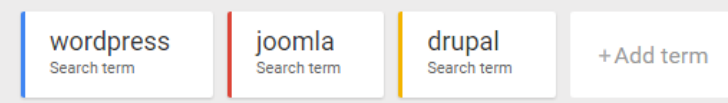

Interest over time

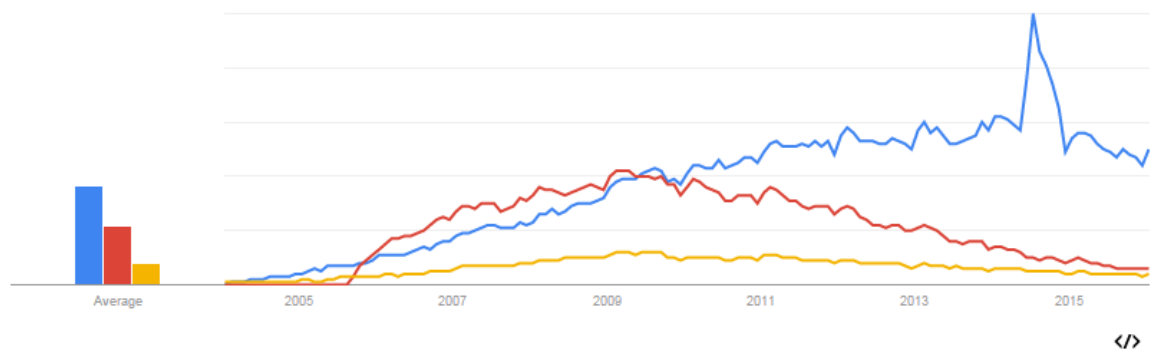

Figure 5. CMS interest building over time (Source: Google Trends, 2016)

\section{BuddyPress}

By using the BuddyPress plug-in of WordPress we can build any type of community, with member profiles, activity streams, user groups, messaging, and more. In fact, BuddyPress transforms WordPress to a platform with social network capabilities.

In 2009, developers released BuddyPress, a series of plug-ins that promised to add 'social networking in a box' to WordPress installations. In practice, this meant that in addition to creating blogs, site members could create profile pages, add friends, write status updates, post notes on one another's profile pages, send private messages, create groups, use discussion forums, and track member activity across the installation. If WordPress created a network of connected blogs, BuddyPress created a social ecosystem around that network (Gold, 2011).

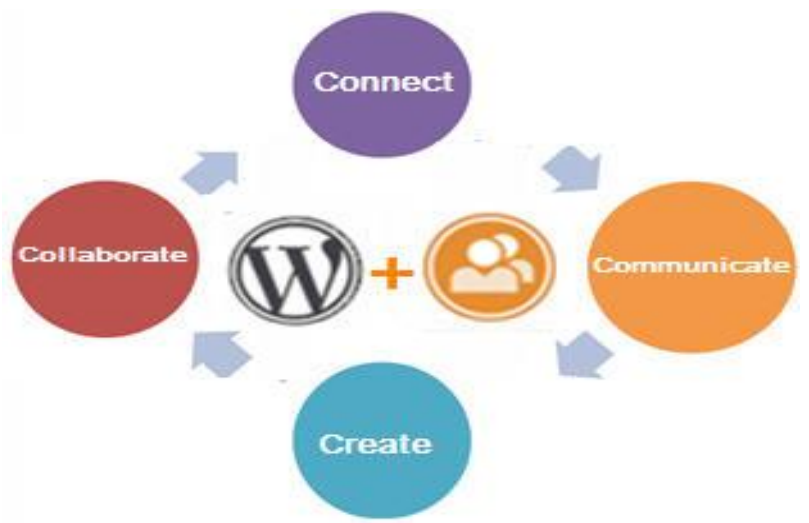

Figure 6: WordPress and BuddyPress interaction (Source http://premium.wpmudev.org)

Although BuddyPress has mimicked functionalities that are part of popular social networking sites, there are some reasons why BuddyPress offers a more attractive option than Facebook or other similar commercial sites (Gold, 2011). More specifically, because it is an open-source platform it can easily be redesigned by both 
teachers and students in order to serve a variety of particular needs. Unlike Facebook discussions, the material does not belong to a private company but to the institution itself. Finally, although it is important 'to meet students where they are', there should be a separation of the personal and professional or vocational profiles, which are involved.

Finally, creating social, academic spaces through tools like BuddyPress, allows teachers and students to participate in subject- or class-specific social networks structured around their educational experiences. They can make course sites more dynamic, social, and interesting without compromising privacy or creating situations that mesh personal and educational networks. In other words, they offer a separation from the life-stream in a way that lowers the stakes of social-networking. A professor can feel free to send a friend request to a student on a BuddyPress course site without worrying that the request will intrude on the student's personal life. Such nostakes social networking can help build goodwill in the context of a course.

\section{BigBlueButton (BBB)}

BBB is an increasingly popular open source conference tool, especially now that DimDim (http://www.dimdim.com) is being discontinued (Aberdour, 2011). BBB has a higher educational focus. It is an active open source project that focuses on usability, modularity, and clean design - both for the user and the developer. It can be used as an independent conferencing platform or as an in-web application (like WordPress) or as an LMS (like Moodle) using the appropriate plug-ins (Papadakis \& Orfanakis, 2013). The screen is split into some areas for web participants, voice participants, presentation, group and private chat, web-cam and desktop sharing. There are three types of roles in the BigBlueButton:

- Viewers can raise their hand to get the attention of the presenter, see other participants, watch presentations, conduct public or private chats, share video using a built-in or external webcam and see where the presenter is pointing at following the indication of a red circle.

- Presenters can mute or eject participants, upload and share any PDF or Office document and share a portion of their desktop or the entire screen.

- Moderators can make anyone a presenter.

\section{Platform Description}

The platform consists of two separate websites. The first site (http://schedu.teicrete.gr/conf) hosts general information such as important dates, the conference venue, key-note speakers, committees, program and the contact information. Apart from this general information, visitors are given the opportunity to be registered on a list to receive updates and messages from the conference organizers by email or address questions by filling out a form. Because of the informative nature of this site no more plug-ins are installed. The chosen theme supports a one-page website and suits the appearance of a conference. On the top right side, there is a link which connects this site to the main platform.

The second site (http://schedu.teicrete.gr/schconf) (Figure 7) has been created to support the student community of the conference members. Specifically, this is the place for members' registration (they have a choice to register as reviewers or participants), abstract submission, platform access and communication between groups consisted of students, teachers and parents. 


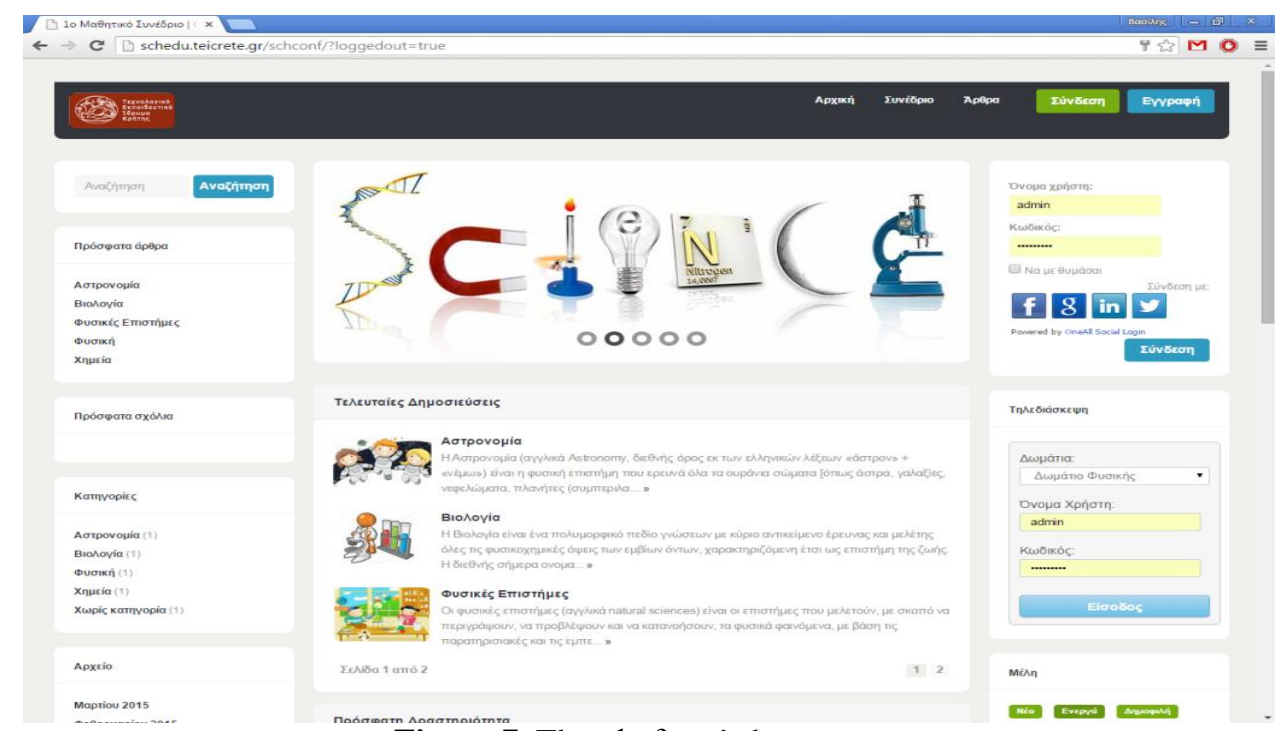

Figure 7. The platform's home page

The main tools offered by the platform are:

- Member registration (participants, reviewers, etc.)

- Profile creation by registered users

- Private conversations

- Making Connections

- Creation of and interaction in or between groups

- Article submission

- Assignment of articles to reviewers

- Communication system

- Virtual Conference System

Although students' details were already known to their teachers, we preferred to let them register themselves using a simple registration form. To make this procedure easier, a detailed user guide was created and distributed containing basic directions for their initial browsing on the platform, and guiding people to perform changes in their profiles, use forums, send e-mails to teachers and peers, etc.

To manage abstracts, a WordPress plug-in (WP Abstracts) was used. Using this plugin, members could easily submit their abstracts having many options like choosing the name and the subject of the conference, author and presenter information, etc. (Figure 8). A special guide for this submission procedure was also generated and distributed. 


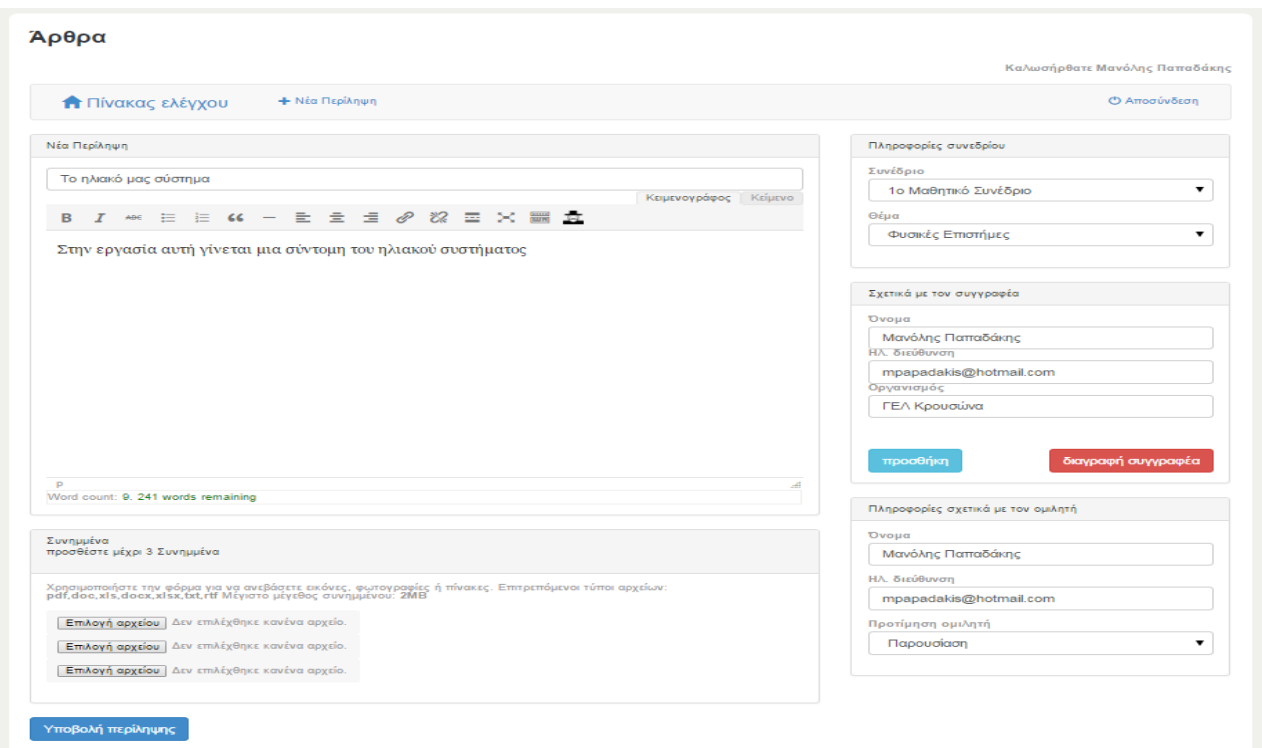

Figure 8. Abstract submission form

The administrator of the platform could easily assign a number of abstracts for review to registered reviewers, who could be either teachers or students (Figure 9). The platform supports blind reviewing to ensure conference reliability.

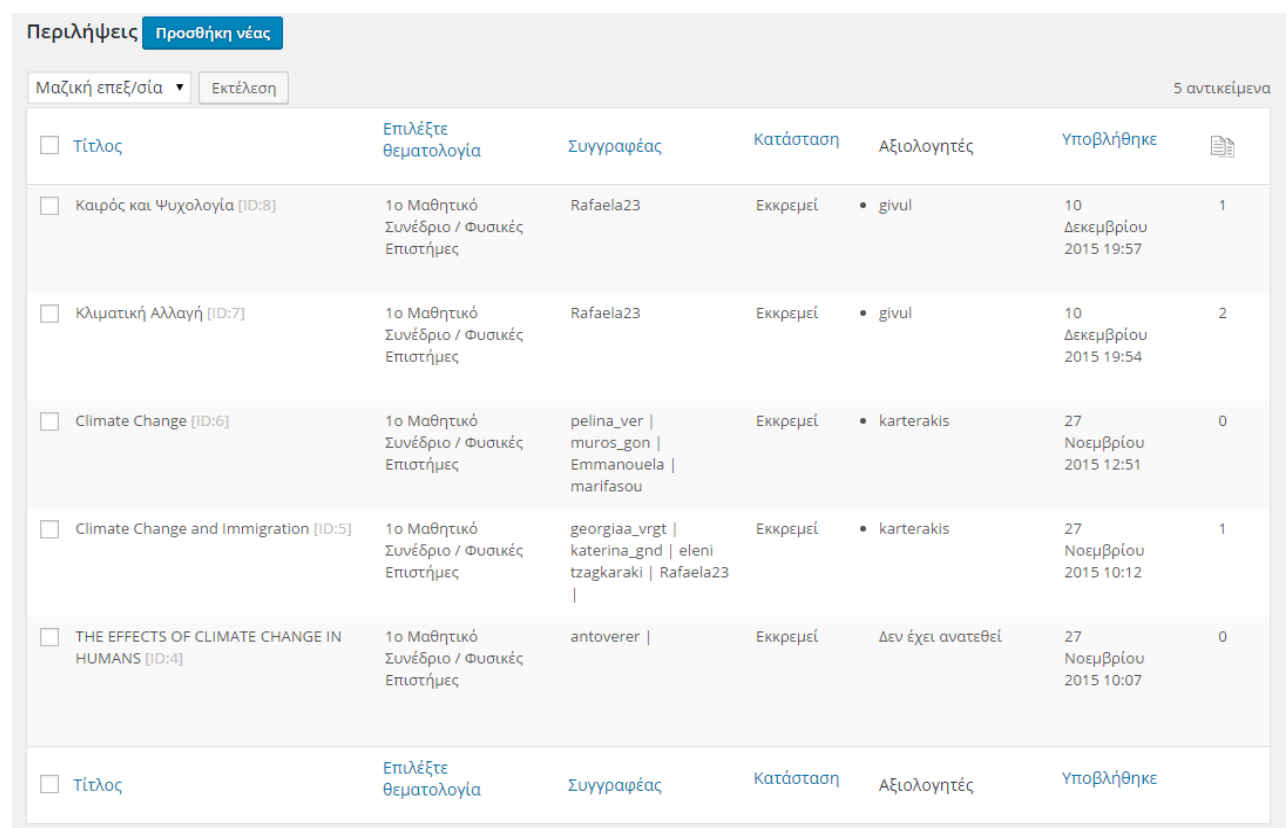

Figure 9. Abstract management

What gives added value to this platform is the ability of members to create profile pages, add friends, write status updates, post notes in one another's profile pages, send private messages, create groups, use discussion forums, and track member activity (Figure 10). Using BuddyPress for this purpose, we ensured that conversations are owned by the students, and there is no undesirable interaction between the personal and educational life of all members. 

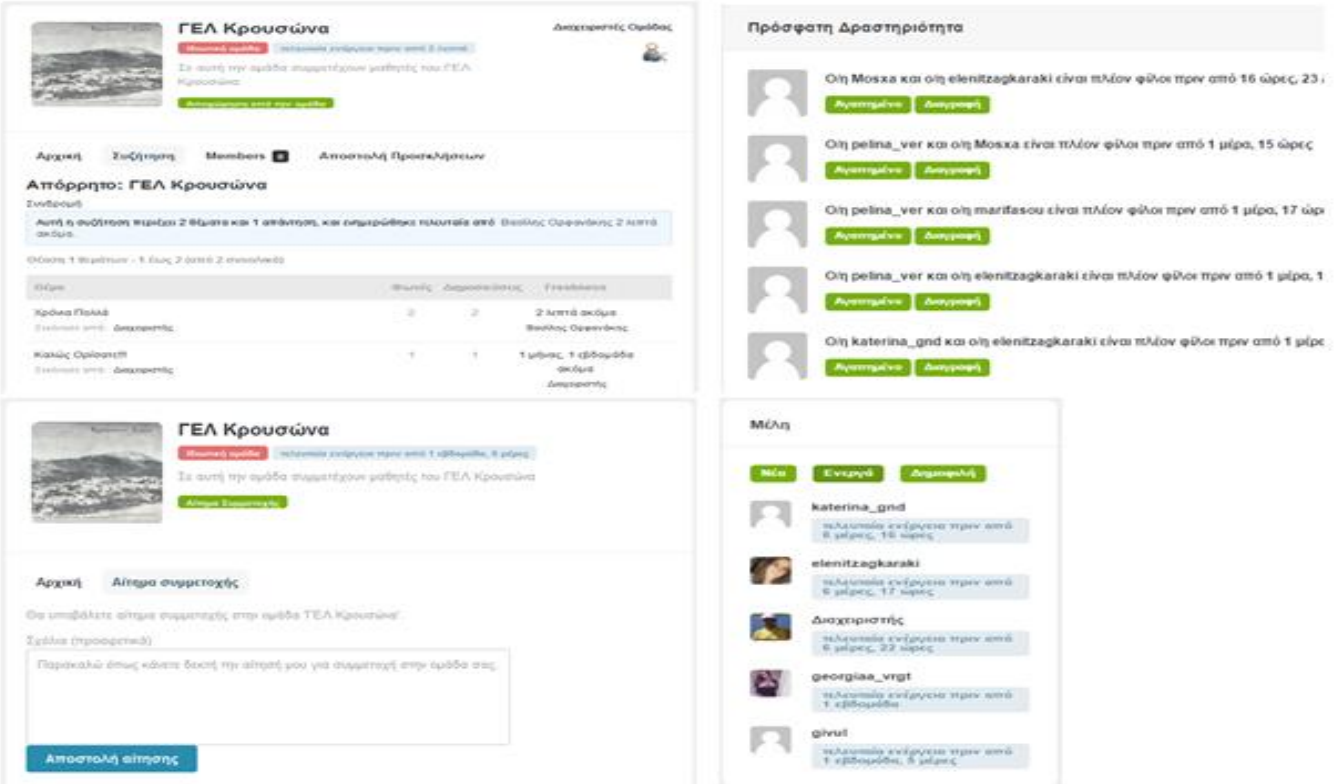

Figure 10. Some of the social network services, which are provided in the platform

The spearhead of the platform is the conference environment which is used for many purposes. The BigBlueButton usage aimed at familiarizing members with participation procedures. In addition, there are separate rooms for discussions according to the project theme. Finally, BBB is used as the base for conferences between schools.

\section{Description of the educational intervention: 'Introduction to Research Projects'} To evaluate the effectiveness of the electronic virtual conference platform and assess its educational effects, an educational intervention was implemented at intraschool and interschool levels. At the intraschool level, the teacher who was responsible for the implementation of a research project in a class of second grade students in a provincial high-school in Crete, during the first semester of the 2015-2016 school year enriched the teaching with the complementary use of the digital platform. $\mathrm{He}$ wanted to simulate the implementation of a student conference on the subject of the given research project. The participants/speakers were students who had also undertaken the role of reviewers, assessing their peers' work. More specifically, students uploaded their work to the platform, received criticism by the reviewers, corrected, modified, enriched, resubmitted and finally presented their work to the digital delegates. At the same time, the teacher taught the research project course to another class at the same school, without using the platform, which enabled us to detect differences in the actualisation of the same course in the same socio-economic environment without the support of the platform.

At the interschool level, teachers in three other provincial high-schools in Crete enriched the implementation of the research project course with participation in the digital student conference. The implementation process of the interschool conference was similar to the intraschool conference with the only difference being that there was no face to face communication between the three school communities and that each reviewer or panel of reviewers focused on the work of other schools. In both cases teachers acted as intermediaries and facilitators at all stages. Students' work was set to meet the objectives of the research projects in each school. Also, the students' work 
could be viewed and displayed either on conventional PCs or on smart mobile devices by parents and classmates.

\section{Results - Evaluation and assessment}

The evaluation and assessment of this combined effort at intraschool and interschool level were based on data collected by the following research tools: (a) interviews with the teachers of participating schools (b) a special questionnaire prepared for the students. The questionnaire was anonymous, and the ethical principles relating to data protection requirements were met (informed consent, confidentiality and permission for the use of data in research reports). In more detail, upon completion of the program the three involved teachers were invited by the researchers to discuss their experience in the form of an interview and comment on the fulfillment of the learning objectives, technical support of the digital platform, strengths and weaknesses of the activity of the student conference, the impact of the digital platform in the implementation of the project course, etc. For a more thorough investigation of the teachers' and students' experience, a questionnaire was developed distributed by the platform, after the completion of the program. It contained structured questions using a Likert five-point scale with scores ranging from 1 (low-acceptance) to 5 (highacceptance).

The qualitative analysis of the interviews showed that teachers believed that pupils developed significantly a variety of communication and technical skills together with project management skills and the ability to collaborate towards the completion of their project. Teachers who followed the traditional approach (without the use of the platform) were differentiated by the contrast in students' motivation and the degree of student cooperation. Typical comments made by the teachers who used the platform were along the lines of "raising the quality of the educational process", "a different type of lesson", or "like teaching to a class of students in another school".

They also claimed that cooperation between students worked well at intraschool and interschool levels, which is confirmed by the usage of the electronic platform. Indicative expressions teachers used during the interviews support the above argument; E.g. they talked about "excellent communication among students", they claimed that "students showed great seriousness and zeal", they said it is "the first time I saw students participate in a course with such fervor", etc. Regarding the interaction between different schools, teachers commented that while some students were initially hesitant to express ideas and exchange views with peers from other schools, the use of the platform helped them to quickly overcome their reservations and actively enroll in all stages. All teachers referred to the functional problems that torment Greek schools, such as the lack of school computer labs and the low-speed Internet connections.

However, there were no negative reports about the use of the platform, and they all commented positively on the compatibility of the platform and its adaptation to navigation via smart mobile devices, (which was often offering the solution to the outdated school equipment and allowed students to use it in out-of-school hours and their spare time). As reported by Apostolou et al. (2014), it was of particular importance that even quiet students, who, in face to face communication, were reluctant to express their opinion, participated happily in this project. It seems that communication over the Internet helps students with lower self-confidence to open up and get more actively involved. Therefore, we found strong indications that the 
appropriate use of the Internet promotes research in students and encourages two-way communication ultimately leading to autonomous activity and 'learning to learn.'

Furthermore, similar conclusions were drawn from the initial statistical analysis of the questionnaire responses (from 47 students). Notable is the positive contribution of the whole intervention to the enhancement of the educational process, the development of digital and $21^{\text {st }}$-century skills, etc. The results were not found to be affected by gender $(F(1,45)=1.46, p>.05)$, or the students' socio-economic background $(F(1,45)=$ $0.95, p>.05)$. A vital indication for the user-friendliness of the platform is that the assessment of the operation of the platform was not affected by students' prior knowledge of ICT $(F(1,45)=1.19, p>.05)$. These results are considered very encouraging as we expected that inclusive online education would meet resistance by a large number of students because of their long experience of the conventional Greek educational system. However, it proves once again that modern teaching methods increasingly support the development of internal motivation in students, encouraging them to participate actively in the learning process building on the curiosity, challenges and satisfaction that grows out of the whole effort. Table 2 shows the student responses to the questionnaire regarding the project results.

Table 2. Student Assessment Questionnaire

\begin{tabular}{|l|l|l|l|}
\hline & Statements & Mean & SD \\
\hline E.1 & $\begin{array}{l}\text { The digital conference increased my interest in the } \\
\text { research project course. }\end{array}$ & 4.4 & 0.42 \\
\hline E.2 & $\begin{array}{l}\text { I happily devoted time for the digital conference outside } \\
\text { school hours. }\end{array}$ & 3.1 & 1.22 \\
\hline E.3 & $\begin{array}{l}\text { I had difficulties in using the electronic platform in terms } \\
\text { of understanding the platform's language. }\end{array}$ & 0.7 & 0.25 \\
\hline E.4 & $\begin{array}{l}\text { I had difficulties in using the electronic platform in terms } \\
\text { of IT skills. }\end{array}$ & 0.5 & 0.20 \\
\hline E.5 & $\begin{array}{l}\text { Cooperation between students from different schools } \\
\text { developed satisfactorily through the platform. }\end{array}$ & 4.4 & 0.84 \\
\hline E.6 & $\begin{array}{l}\text { I believe that the digital conference contributed to the } \\
\text { development of my IT knowledge and skills. }\end{array}$ & 4.6 & 0.52 \\
\hline E.7 & $\begin{array}{l}\text { I would like to have the digital platform permanently at my } \\
\text { disposal for both the research project course and for other } \\
\text { courses. }\end{array}$ & 4.8 & 0.60 \\
\hline
\end{tabular}

\section{Conclusion - Discussion}

The introduction of ICT brings new challenges to the educational system. ICT enables multiple representations of concepts, fosters experimental work and enables the creation of models and problem-solving applications (Psycharis et al., 2013). Traditional teaching methods, with teachers giving long lectures in front of a blackboard, are not effective with today's students and are not expected to work with the students of tomorrow (Stasinakis \& Kalogiannakis, 2015). Often ICT is utilized internationally as an alternative to the traditional - conventional teaching and learning methods to meet the needs of students in both Primary and Secondary Education (Chatziplis et al., 2006). In the era of Information and Communication Technologies, tools are available online and can very easily be used in the educational process. Multi-faceted distance learning (Lionarakis, 1998) sets the conditions for longdistance, collaborative knowledge building environments, which encourage inquiry 
and critical thinking, activating self-directed and independent learning based on a heuristic inquiry. However, in our country, with some exceptions (Stasinakis \& Kalogiannakis, 2015) the use of ICT in learning is completely absent in primary and secondary education; something which has provided the impetus for this study and search for possible solutions.

In this study, the setting up of a digital internet platform, which uses Web 2.0 tools, aims to help and strengthen the educational and learning process in an innovative way focusing on students' conference sessions. Students are invited to escape the confines of traditional, conventional schooling, which promote memorization and remove every trace of creativity and discovery. They get the experience of participating in a digital community that uses distance education tools for information, communication, collaboration and learning. The use of the platform transforms the student from a passive recipient to a knowledge creator and aids in developing skills related to thinking and knowledge building processes (Panagiotakopoulos et al., 2003).

The role-playing game (that students enact in the context of the digital conference presentation) is considered to increase students' interest and contribute to the development of a variety of skills. The implementation of a more student-centered approach to knowledge, transfers responsibilities and powers to students by supporting the development of internal motivation. Students' satisfaction is increased, which, in effect, leads them to redoubling efforts for the learning objectives. Consequently, this type of learner-centered approaches has better results than the more traditional teaching models (particularly in relation to the promotion of learning and skills development) (Drenoyianni, 2010). At this point, we must not overlook the particular role of the teacher who tranforms also and becomes a leader and facilitator of discovery and information processing (Anastasiades, 2009).

Contrary to the popular belief, the positive effects of ICT should not be taken for granted. The simple use of ICT tools by and on itself does not ensure computer use as a cognitive tool (Kalogiannakis, 2008). However, the increased interactivity and attractiveness of a digital environment allowed students to acquire holistic knowledge within a modern learning environment supported by ICT. Students working in a competitive environment, enjoyed the online collaboration and were led - as far as was possible - to the nurturing of critical social and cognitive skills. That is, the development or improvement of 21 st-century skills such as cooperation, responsibility, adaptability, etc. In conclusion, the overall results of the teaching intervention were considered to be very positive. Although the students were not prepared by the wider school culture for working together, or analyzing and synthesizing data either in person, or online, they responded with particular responsibility to their new roles.

\section{Research limitations - Future perspectives}

In recent years, there is ample supportive evidence for the educational use of Web 2.0 services. Innovative teaching activities can be found throughout scientific publications and research activities, most of them focusing either on higher education or the final grades of secondary education. Apart from the theoretical knowledge that is offered by an educational system, new ways of acquiring knowledge through experiential activities should be found. The organization of a digital conference by students offers this opportunity to the participants who develop multiple skills (McLoughlin \& Lee, 2010). 
The present teaching intervention - which is actually a case study - has various limitations. Its short, the small number of teachers and students and the limited geographic spread of the application do not allow safe conclusions and generalizations. This left us with the need to study the use of the platform for the implementation of the Research Project course, in collaboration with students from many different schools and from different regions in the near future. The translation of the platform into other languages will give the opportunity for school partnerships between different countries too. This will enable schools to learn together, share their views and create new friendships. Also, taking into consideration the results of this first case study, we will proceed with the enrichment of the platform. This could be easily achieved, since a wide range of plug-ins is already available. We also plan to conduct the first digital student conference in Greece with the participation of Secondary Education students from Greece and Cyprus in collaboration with the University of Crete and the Technological Institute of Crete. Finally, our intention is to provide the platform as open source software to the wider education community, so that it serves as an additional educational tool for teachers.

In summary, the present study provides another impetus for the introduction of modern education systems to secondary schools. Of course, this should be supported by the official state since measures must be taken towards reforming the formal education system, preferably by replacing the tight curriculum and opening up towards mixed modes of learning and investing in human resources (training teachers in new forms of learning through the use of ICT) and finally by modernizing the existing technical infrastructure.

\section{References}

Aberdour, M. (2011). Virtual classrooms: an overview. Kineo. Retrieved 20 January 2016 from http://goo.gl/BWCK39

Anastasiades, P. (2005). Synchronous Vs Asynchronous Learning: Principles, Methodology and Implementation Policy of a Blended Learning Environment for Lifelong Learning at the University of Crete. In P. Kommers and G. Richards (Eds.), Proceedings of World Conference on Educational Multimedia, Hypermedia and Telecommunications (pp. 2166-2172), Chesapeake, VA: AACE.

Anastasiades, P. (2009). Interactive Videoconferencing and Collaborative Distance Learning for K-12 Students and Teachers: Theory and Practice. New York: Nova Science Publishers.

Anastasiades, P., \& Kotsidis, K. (2013). The Challenges of Web 2.0 for Education in Greece: A Review of the Literature. International Journal of Web-Based Learning and Teaching Technologies (IJWLTT), 8(4), 19-33.

Anastasiades, P., Filippousis, G., Karvunis, L., Siakas, S., Tomazinakis, A., Giza, P., \& Mastoraki, H. (2010). Interactive Videoconferencing for collaborative learning at a distance in the school of 21 st century: A case study in elementary schools in Greece. Computers and Education, 54(2), 321-339.

Anastasiou, A., Androutsou, D., \& Georgalas, P. (2014). E-debate: Using Web 2.0 tools through an open eClass environment to develop a virtual debate in English for elementary school pupils. ICT \& Innovations in Education, 2(3), 31-38.

Apostolou, M., Antoniou, P., \& Papastergiou, M. (2014). Distance collaborative education within the framework of digital learning communities as a medium to develop social skills in environmental education. Open Education - The Journal for Open and Distance Education and Educational Technology, 10(1), 33-48 (In Greek).

Baker, S., Wentz, R., \& Woods, M. (2009). Using Virtual Worlds in Education: Second Life ${ }^{\circledR}$ as an Educational Tool. Teaching of Psychology, 36(1), 59-64.

Bell, S. (2010). Project-based learning for the 21st century: Skills for the future. The Clearing House, 83(2), 39-43. 
Bradley, J. (Ed.) (2003). The Open Classroom: Distance learning in and out of schools. London: Kogan Page.

Chatziplis, P., Vassala, P., \& Lionarakis, A. (2006). Supplementary distance learning in secondary education. Proceedings of the $2^{\text {nd }}$ International Open and Distance Learning (IODL) Symposium having as the main theme: Lifelong open \& flexible learning in the globalized world, September 13-15 (pp. 189-202). Turkey: Eskisehir.

Drenoyianni, H. (2010). The 'new school' and the role of ICT as an educational reform tool. In A. Jimoyiannis (Ed.), Proceedings of the 7th Pan-Hellenic Conference with International Participation 'Information and Communication Technologies in Education', Hellenic Association of ICT in Education (HAICTE), 23-26 September 2010, (pp. 593-600), GreeceKorinthos: HAICTE (in Greek).

Gold, M. (2011). Beyond Friending: BuddyPress and the Social, Networked, Open-Source Classroom. In R.-T. Scholz (Ed.), The Politics of Digital Culture Series Learning Through Digital Media Experiments in Technology and Pedagogy, (pp. 69-78), New York: The Institute for Distributed Creativity.

Google Trends (2016). Google Trends - Compare CMS. Retrieved 24 January 2016 from http://goo.gl/Mm8UyH

Jimoyiannis, A. (2012). Editorial: Special issue "Investigating the Educational Web 2.0". Themes in Science and Technology Education, 5(1/2), 1-4.

Jimoyiannis, A., \& Angelaina, S. (2012). Towards an analysis framework for investigating students' engagement and learning in educational blogs. Journal of Computer Assisted Learning, 28(3), 222-234.

Jimoyiannis, A., Tsiotakis, P., Roussinos, D., \& Siorenta, A. (2013). Preparing teachers to integrate Web 2.0 in school practice: Toward a framework for Pedagogy 2.0. Australasian Journal of Educational Technology, 29(2), 248-267.

Kalogiannakis, M. (2008). From Learning to Use ICT to Use ICT for Learning: Technological Capabilities and Pedagogical Principles, In R. Kobayashi (Ed.), New Educational Technology, (pp. 13-42), New York: Nova Publishers.

Kalogiannakis, M. (2010). Training with ICT for ICT from the trainer's perspective. A Greek case study. Education and Information Technologies, 15(1), 3-17.

Leary, S. (2010). Beginnin Wordpress 3 (1st Edition). Apress, Berkely, CA, USA.

Lionarakis, A. (1998). Polymorphic Education: A Pedagogical framework for open and distance learning., In A. Szucs A. \& Wagner A. (Eds.), Universities in a Digital Era - Transformation, Innovation and Tradition - Roles and Perspectives of Open and Distance Learning (pp. 499 505). European Distance Education Network (EDEN): University of Bologna.

McLoughlin, C., \& Lee, M. J. (2010). Personalised and self regulated learning in the Web 2.0 era: International exemplars of innovative pedagogy using social software. Australasian Journal of Educational Technology, 26(1), 28-43.

Matsagouras, H. (2011). The Novelty of Research Project in New High School, Teacher's Book. Athens: Greek Pedagogical Institute (in Greek).

Maureen, T. (2000). Constructivism, Instructional Design, and Technology: Implications for Transforming Distance Learning. Educational Technology \& Society, 3(2), 50-60.

McBrien, J. L., Jones, P., \& Cheng, R. (2009). Virtual spaces: Employing a synchronous online classroom to facilitate student engagement in online learning. The International Review of Research in Open and Distance Learning, 10(3) Retrieved on 10 January, 2016 from http://www.irrodl.org/index.php/irrodl/article/view/605/1264

Official Journal of the European Union (2015). 2015 Joint Report of the Council and the Commission on the implementation of the strategic framework for European cooperation in education and training (ET 2020) - New priorities for European cooperation in education and training. Retrieved on 15 January, 2016 from http://eur-lex.europa.eu/legalcontent/EN/TXT/?uri=CELEX:52015XG1215(02)

Palloff, R., \& Pratt, K. (1999). Building Learning Communities in Cyberspace. San Francisco: Jossey Bass Inc.

Panagiotakopoulos, C., Lionarakis, A., \& Xenos, M. (2003). Open and Distance Learning: Tools of Information and Communication Technologies for Effective Learning. Proceedings of the $6^{\text {th }}$ Hellenic-European Conference on Computer Mathematics and its Applications, HERCMA 2003 (pp. 361-367). Athens: Greece. 
Panagiotakopoulos, C., Tsiatsos, T., Lionarakis, A., \& Tzanakos, N. (2015). Teleconference in support of distance learning: Views of educators. Open Education - The Journal for Open and Distance Education and Educational Technology, 11(1), 38-50.

Papadakis, S., Kalogiannakis, M., Orfanakis, V., \& Zaranis, N. (2014). Novice Programming Environments. Scratch \& App Inventor: a first comparison. In H. M. Fardoun \& J. A. Gallud (Eds.), Proceedings of the 2014 Workshop on Interaction Design in Educational Environments (IDEE '14). New York: ACM.

Papadakis, St., Kalogiannakis, M., Zaranis, N., \& Orfanakis, V. (2016). Using Scratch and App Inventor for teaching introductory programming in secondary education. A case study. International Journal of Technology Enhanced Learning (Forthcoming article)

Papadakis, St., \& Orfanakis, V. (2013). Teleconferences using open source tools. The case of BigBlueButton. Proceedings of the 7th Panhellenic Conference of Informatics Teachers (PEKAP). Thessaloniki: Greece (in Greek).

Papadakis, St., \& Orfanakis, V. (2014a). Cloud services in education. Proceedings of the Panhellenic Conference Education in ICT era. Athens: Greece (in Greek).

Papadakis, St., \& Orfanakis, V. (2014b). Web 2.0 in the educational process. Using Weebly in teaching the course Multimedia Networks. Proceedings of the Panhellenic Conference Education in ICT era. Athens: Greece (in Greek).

Papastergiou, M., Antoniou, P., \& Apostolou, M. (2011). Effects of student participation in an online learning community on environmental education: A Greek case study. Technology, Pedagogy and Education, 20(2), 127-142.

Psycharis, S., Chalatzoglidis, G., \& Kalogiannakis, M. (2013). Moodle as a learning environment in promoting conceptual understanding for secondary school students. Eurasia Journal of Mathematics, Sciences \& Technology Education, 9(1), 11-21.

Roblyer, M.-D. (2003). Virtual high schools in the United States: Current views, future visions. In J. Bradley (Ed.). Distance Learning In and Out of Schools: The Open Classroom, (pp. 118-126), London and Sterling: Kogan Page.

Sabin-Wilson, L. (2010). BuddyPress for Dummies. New York: Wiley Publishing, Inc.

Spanos, D., \& Sofos, A. (2014). Digital literacy of students participating in a one-to-one laptop initiative in Greece. Open Education - The Journal for Open and Distance Education and Educational Technology, 10(1), 69-76.

Stasinakis, P., \& Kalogiannakis, M. (2015). Using Moodle in secondary education: A case study of the course "Research Project" in Greece. International Journal of Education and Development using Information and Communication Technology (IJEDICT), 11(3), 50-64.

Theofanellis, T. (2014). Research Projects: proposals for solving frequent problems. Erkyna, Journal of teaching and scientific topics, 2, 51-62 (in Greek).

UNESCO (2002). Open and Distance Learning, Trends, policy and strategy Considerations. Moore, M., (Eds) Paris, Retrieved on 15 January, 2016 from http://unesdoc.unesco.org/images/0012/001284/128463e.pdf

Xie, K., Debacker, T.-K., \& Ferguson, C. (2006). Extending the traditional classroom through online discussion: the role of student motivation. Journal of Educational Computing Research, 34(1), 67-89. 